\title{
Risk factors associated with congenital hypothyroidism: a case-control study in southeast Iran
}

\author{
Mohammad Khammarnia ${ }^{1}$, Fariba Ramezani Siakhulak ${ }^{2}$, Hossein Ansari ${ }^{3}$, Mostafa Peyvand ${ }^{4}$
}

${ }^{1}$ Ph.D., Assistant Professor, Health Promotion Research Center, Zahedan University of Medical Sciences, Zahedan, Iran

${ }^{2}$ M.Sc., Department of Epidemiology and Biostatistics, School of Public Health, Health Promotion Research Center, Zahedan University of Medical Sciences, Zahedan, Iran

${ }^{3}$ Ph.D., Department of Epidemiology and Biostatistics, School of Public Health, Health Promotion Research Center, Zahedan University of Medical Sciences, Zahedan, Iran

${ }^{4}$ Health Promotion Research Center, Zahedan University of Medical Sciences, Zahedan, Iran

\section{Type of article: Original}

\begin{abstract}
Background and aim: Congenital hypothyroidism $(\mathrm{CH})$ is known as one of the most common preventable cause of mental retardation. This study aimed to determine factors associated with $\mathrm{CH}$ in Iran.

Methods: This case-control study was conducted on 160 children under one year old in Zahedan in southeast Iran in 2016. The neonates who were born from March 1, 2015 to March 19, 2016 and had undergone a screening program for $\mathrm{CH}$ were the study population. The neonates with serum $\mathrm{TSH}>10 \mathrm{mIu} / \mathrm{L}$ and $\mathrm{T} 4<6.5$ or TSH $>30$ $\mathrm{mIu} / \mathrm{L}$ were considered as a case group. Each case was individually matched for sex, age at birth and place of residence with three neonates with normal TSH and T4 titers as a control group. Data was gathered using a standard checklist and analyzed using SPSS 20 and statistical tests, such as Chi-square and Fisher's exact tests. Multivariable logistic regression analysis was also used to identify independent predictors of $\mathrm{CH}$.

Results: About 25 of the 40 patients with $\mathrm{CH}(62.5 \%)$ were male who, in the univariate analysis, the following explanatory factors had no significant association with $\mathrm{CH}$ : history of parental consanguinity, type of delivery, weight at birth, height at birth, age of mother, sampling time, nationality, and birth season ( $>0.05)$. Although, multivariate analysis showed no significant association between the studied factors and risk of $\mathrm{CH}(\mathrm{p}>0.05)$, the likelihood of $\mathrm{CH}$ was greater among neonates born to consanguineous parents (AOR: 1.78, 95\% CI: 0.82-3.89), those who were born to lower height at birth (AOR: 1.82, 95\% CI: 0.85-3.91), neonates born to mothers younger than 18 years (AOR: 2.43, 95\% CI: 0.57-10.29) and those who were born in the summer (AOR: $1.76,95 \%$ CI: 0.57-5.44).

Conclusion: None of the studied factors were predictors for $\mathrm{CH}$. Since consanguineous marriages are frequent in the province, and it may be a major contributory factor, future studies should be conducted on the genetic causes.

Keywords: Congenital hypothyroidism, Risk Factors, Iran
\end{abstract}

\section{Introduction}

Congenital hypothyroidism $(\mathrm{CH})$ is known as one of the most common preventable causes of mental retardation (1), and also considered a major preventable and detectable cause of mental retardation with early and simple treatment (2). $\mathrm{CH}$ is caused by dysfunction of the hypothalamus-pituitary- thyroid axis (1) and lack of thyroid hormones at birth in newborns (3). Thyroid hormones have an invaluable role in maintaining mental development in children (4). Most infants with $\mathrm{CH}$ at birth often have a normal appearance and non-specific clinical symptoms and signs. Thus, if diagnosis is made based only on clinical symptoms, newborns will suffer from irreversible complications such as neurological damage (5), slow growth, delayed skeletal maturation $(3,4)$, and mental retardation (4). Therefore, screening programs which were developed in the early 1970's and accepted by many countries worldwide (6), are

\section{Corresponding author:}

Fariba Ramezani Siakhulak, Department of Epidemiology and Biostatistics, School of Public Health, Health Promotion Research Center, Zahedan University of Medical Sciences, Zahedan, Iran.

Tel: +98.9156387699, Email: gilanehf@gmail.com

Received: August 10, 2017, Accepted: November 27, 2017, Published: February 2018

iThenticate screening: November 09, 2017, English editing: January 12, 2018, Quality control: January 15, 2018

This article has been reviewed / commented by four experts

(C) 2018 The Authors. This is an open access article under the terms of the Creative Commons Attribution-NonCommercialNoDerivs License, which permits use and distribution in any medium, provided the original work is properly cited, the use is non-commercial and no modifications or adaptations are made. 
the only effective way to diagnose and treat $\mathrm{CH}$. In this regard, a screening program for $\mathrm{CH}$ was carried out in Iran in 1987 (8). Currently, screening programs are used in developed and developing countries (7) by measuring Thyroid-Stimulating Hormone (TSH) and thyroxin (T4) (3) through cord blood and heel blood samples (5). Diagnosis and timely treatment of $\mathrm{CH}$, significantly reduces mental disability and irreversible neurological damage (2). The prevalence of $\mathrm{CH}$ is reported in different regions, as in Turkey 1:2736, in Pakistan 1:781, in Black America 1:10,000(9) and in Nigeria 1:67.1 (10). Moreover, the average incidence of $\mathrm{CH}$ worldwide is estimated at around 1 in 3000-4000 live births, which is higher than the average incidence of hypothyroidism in the world (11). There are some variations in different areas of Iran such as Tehran and Isfahan which found the average prevalence of $\mathrm{CH}$ at 1:914 and 1:338 live birth, respectively (11). Several studies have investigated different prognostic factors of $\mathrm{CH}$ $(12,13)$, that indicates the influence of several genetic and environmental factors on the incidence of this disease (12). More practically, it could be helpful to have a higher index of suspicion for $\mathrm{CH}$ in neonates with the identified risk factors. However, to date, no study has been conducted in Sistan and Baluchestan province for exploring probable causes related to hypothyroidism. On the other hand, due to the high prevalence of $\mathrm{CH}$ in Zahedan as the capital of the province, the aim of this study was to determine related factors with $\mathrm{CH}$ in Sistan and Baluchestan as the widest and poorest region in Iran.

\section{Material and Methods}

This case-control study was conducted in Zahedan in southeast Iran in 2016, based on the available data in the medical records of neonates who had undergone a $\mathrm{CH}$ screening program in a public health center. The study population were children under one-year old who were born in Zahedan between March 1, 2015 and March 19, 2016, and had undergone a CH screening program. The neonates who had incomplete medical records in the local health centers were excluded from the study. In the screening program, blood samples had already been taken from all neonates' heel in order to detect hypothyroidism in early neonatal period. According to the guidelines of the Ministry of Health and Medical Education in Iran, levels of thyroid-stimulating hormone (TSH) $>10 \mathrm{mU} / \mathrm{L}$ and a T4 level $<6.5 \mathrm{mg} / \mathrm{dL}$ allow the diagnosis of $\mathrm{CH}$. In addition, infants with a TSH level $\geq 20 \mathrm{mU} / \mathrm{L}$ were referred to a specialist for specific surveillance (14). The neonates with $\mathrm{CH}$ were considered as cases. On the other hand, infants who had TSH levels $<5 \mathrm{mU} / \mathrm{L}$, obtained using the method outlined above or an intravenous test of TSH with results of 1.7 to $9.9 \mathrm{mU} / \mathrm{L}$ and a T4 level of 6.5 to 16.3 , were considered normal (14). To increase the power of the study, more than one control was selected per case and for each case, three neonates with normal TSH and T4 titers were randomly selected as control from the same health centers. Thus, several blocks were randomly selected in the health centers and from the same blocks several household records were randomly selected for the controls. Accordingly, the cases were frequency matched with the associated controls based on sex, age at birth and place of residence. Therefore, the study cases and controls were selected based on census and simple randomization methods, respectively. We investigated the effect of potential risk factors on congenital hypothyroidism. The available data were extracted directly from the neonates' medical records using a standard checklist including demographic characteristics of neonates such as sex, weight at birth, height at birth, nationality, the place of residence, the birth season and age of the neonate at the time of sampling, and parents' demographic characteristics such as type of delivery, age of mother, and consanguinity parents. The data were analyzed with statistical tests, such as Chi-square and Fisher exact test using IBMC SPSS $\odot$ Statistics version 20 (IBM $\odot$ Corp., Armonk, NY, USA). A binary analysis was used to describe the association between independent and dependent variables. A multivariable logistic regression analysis identified determinants of $\mathrm{CH}$ at $95 \% \mathrm{CI}$ and $\mathrm{p}<0.05$. The final model was fitted using the Adjusted $\mathrm{x}^{2}$ Goodness of Fit test. According no extra intervention was performed for these samples and; therefore, there was no ethical issue in the data gathering. Moreover, the Ethics Committee of Zahedan University of Medical Sciences approved this study (ref. no.: 7927).

\section{Results}

This study was carried out on the 160 children with or without a history of $\mathrm{CH}$ ( 40 with $\mathrm{CH}$ and 120 with no history of hypothyroidism). According to results, 25 of 40 patients (62.5\%) were male that the proportion was higher in males than females. The demographic variables are shown in Table 1. Crude and adjusted odds ratios were computed for each explanatory variable to determine the strength of association and control confounders. To assess the association between the different factors and $\mathrm{CH}$, bivariate analysis was done. All independent variables with $\mathrm{p}<$ 0.2 were taken as a cut-off point to select variables for the multiple logistic regression models. Then, variables with $\mathrm{p}<0.05$ were used to fit the final multivariate logistic regression model. The unadjusted and adjusted odds ratios together with their $95 \%$ confidence intervals were computed. According to the univariate logistic regression analysis, there was no significant association between a history of parental consanguinity and $\mathrm{CH}(\mathrm{p}=0.09)$; however, odds ratio (OR) of $\mathrm{CH}$ in infants who were born to consanguineous parents was 1.86 times greater than 
others [COR: 1.86, 95\% CI: 0.89-3.89). The probability of $\mathrm{CH}$ occurrence was 2 times higher in low height neonates than that of normal or high height neonates (COR: 2, 95\% CI: 0.96-4.14); however, there was no significant association $(\mathrm{p}=0.06)$. Also, there was no significant difference between the occurrence of $\mathrm{CH}$ and weight at birth either $(\mathrm{p}=0.65)$.However, the $\mathrm{OR}$ estimate of $\mathrm{CH}$ was 1.46 times in neonates with lower weight than $2500 \mathrm{gr}$ compared to neonates with normal weight (2500-3500) (COR: $1.46,95 \% \mathrm{CI}: 0.51-4.19)$. The probability of $\mathrm{CH}$ occurrence was 2.88 times higher than the neonates who were born from mothers younger than 18 years compared to the neonates who were born with mothers of normal age (18-35) years (COR: 2.88, 95\% CI: 0.72-11.53); however, there was no significant association $(\mathrm{p}=0.25)$. Moreover, the probability of $\mathrm{CH}$ occurrence was 1.47 times higher than the neonates who were born from mothers older than 35 years compared to the neonates who were born with mothers of normal age (18-35) years (COR: 1.47, 95\% CI: 0.64-3.36); however, there was no significant association $(\mathrm{p}=0.25)$. On the other hand, there was no statistical association between $\mathrm{CH}$ and type of delivery, time of screening, nationality, and birth season ( $p>0.05$ ) (Table 1). According to results, multivariate logistic regressions analysis showed no significant association between the studied factors and risk of $\mathrm{CH}$ among the children ( $>0.05)$. However, $\mathrm{OR}$ of $\mathrm{CH}$ in neonates who were born from consanguineous parents were 1.78 times greater than neonates who were born from parents without consanguinity (AOR: $1.78,95 \% \mathrm{CI}$ : $0.82-3.89$ ). The probability of $\mathrm{CH}$ occurrence was 1.82 times higher in the low height neonates than those with normal or high height (AOR: 1.82, 95\% CI: $0.85-3.91)$. The probability of $\mathrm{CH}$ occurrence was 2.43 times higher than the neonates who were born from younger mothers compared with others (18-35) years (AOR: 2.43, 95\% CI: 0.57-10.29). Table 2 shows the results of multivariate (adjusted) logistic regression analysis of the effects of neonates' characteristics on $\mathrm{CH}$.

Table 1. Analysis of univariate (unadjusted) logistic regression by the characteristics of all neonates with (case) or without (control) $\mathrm{CH}$

\begin{tabular}{|c|c|c|c|c|c|c|c|}
\hline \multicolumn{2}{|l|}{ Variable } & \multicolumn{2}{|c|}{ Case } & \multicolumn{2}{|c|}{ Control } & \multirow{2}{*}{$\begin{array}{l}\text { Crude OR } \\
(95 \% \mathrm{CI})\end{array}$} & \multirow[t]{2}{*}{ p-value } \\
\hline & & $\mathrm{n}$ & $\%$ & $\mathrm{n}$ & $\%$ & & \\
\hline \multirow[t]{2}{*}{ Type of delivery } & Normal & 28 & 23.5 & 91 & 76.5 & Ref. & \multirow[t]{2}{*}{0.56} \\
\hline & Caesarean & 12 & 28 & 31 & 72 & $1.26(0.57-2.77)$ & \\
\hline \multirow[t]{2}{*}{ History of consanguineous marriage } & Yes & 26 & 30 & 61 & 70 & $1.86(0.89-3.89)$ & \multirow[t]{2}{*}{0.09} \\
\hline & No & 14 & 18.7 & 61 & 81.3 & Ref. & \\
\hline \multirow[t]{2}{*}{ Height at birth (cm) } & $<50$ & 21 & 31.8 & 45 & 68.2 & $2(0.96-4.14)$ & \multirow[t]{2}{*}{0.06} \\
\hline & $\geq 50$ & 18 & 19 & 77 & 81 & Ref. & \\
\hline \multirow[t]{3}{*}{ Weight at birth (gr) } & $2500-3500$ & 29 & 24 & 92 & 76 & Ref. & \multirow[t]{3}{*}{0.65} \\
\hline & $<2500$ & 6 & 31.6 & 13 & 68.4 & $1.46(0.51-4.19)$ & \\
\hline & $>3500$ & 4 & 19 & 17 & 81 & $0.75(0.23-2.39)$ & \\
\hline \multirow[t]{3}{*}{ Age of mother (years) } & $18-35$ & 25 & 21.7 & 90 & 78.3 & Ref. & \multirow[t]{3}{*}{0.25} \\
\hline & $<18$ & 4 & 44.4 & 5 & 55.6 & $2.88(0.72-11.53)$ & \\
\hline & $>35$ & 11 & 29 & 27 & 71 & $1.47(0.64-3.36)$ & \\
\hline \multirow[t]{2}{*}{ Sampling time (days) } & $3-5$ & 17 & 25.4 & 50 & 74.6 & Ref. & \multirow[t]{2}{*}{0.81} \\
\hline & $>5$ & 23 & 27.1 & 62 & 72.9 & $1.09(0.53-2.26)$ & \\
\hline \multirow[t]{2}{*}{ Nationality } & Iranian & 39 & 24.5 & 120 & 75.5 & $0.65(0.06-7.36)$ & \multirow[t]{2}{*}{1.00} \\
\hline & Afghani & 1 & 23.3 & 2 & 66.7 & Ref. & \\
\hline \multirow[t]{4}{*}{ Birth season } & Spring & 15 & 39.5 & 23 & 60.5 & Ref. & \multirow[t]{4}{*}{0.09} \\
\hline & Summer & 8 & 18.6 & 35 & 81.4 & $0.35(0.13-0.95)$ & \\
\hline & Fall & 10 & 18.5 & 44 & 81.5 & $0.34(0.13-0.89)$ & \\
\hline & Winter & 7 & 25.9 & 20 & 74.1 & $0.53(0.18-1.58)$ & \\
\hline
\end{tabular}

Table 2. Results of multivariate (adjusted) logistic regression analysis of the effects of neonates' characteristics on $\mathrm{CH}$

\begin{tabular}{|l|l|l|l|}
\hline Variable & Adjusted OR & $95 \%$ CI \\
\hline \multirow{2}{*}{$\begin{array}{l}\text { History of consanguineous } \\
\text { marriage }\end{array}$} & Yes & Ref. & - \\
\cline { 2 - 4 } & No & 1.78 & $0.82-3.89$ \\
\hline \multirow{2}{*}{ Height at birth (cm) } & $<50$ & 1.82 & $0.85-3.91$ \\
\cline { 2 - 4 } & $\geq 50$ & Ref. & - \\
\hline \multirow{3}{*}{ Age of mother (years) } & $18-35$ & Ref. & - \\
\cline { 2 - 4 } & $<18$ & 2.43 & $0.57-10.29$ \\
\cline { 2 - 4 } & $>35$ & 1.31 & $0.53-3.17$ \\
\hline \multirow{3}{*}{ Birth season } & Spring & Ref. & - \\
\cline { 2 - 4 } & Summer & 1.76 & $0.57-5.44$ \\
\cline { 2 - 4 } & Fall & 0.74 & $0.22-2.43$ \\
\cline { 2 - 4 } & Winter & 0.69 & $0.22-2.15$ \\
\hline
\end{tabular}




\section{Discussion}

Several studies have investigated different prognostic factors on $\mathrm{CH}(12,13)$. Identification of risk factors for this condition can improve diagnosis or treatment plan of these neonates. The study results showed that boys were at higher risk of $\mathrm{CH}$ than girls. Anastasovska et al. concluded that the risk of $\mathrm{CH}$ was higher among boys (15). Many reports have indicated that $\mathrm{CH}$ is frequently found in girls $(16,17)$. Medda et al. conducted a case-control study in order to determine risk factors for $\mathrm{CH}$, and reported higher prevalence of $\mathrm{CH}$ among females than males (16). Akha et al. reported that the female/male ratio of $\mathrm{CH}$ was approximately 1.0 (10). The difference may be due to the role of sex hormones in relation to this disease that probably provides proper background to incidence of the autoimmune disease, and to supply necessary antigens for the disease as well as to create apoptosis in follicle cells of the thyroid (18). Due to the matching individuals in this study, the relationship between gender and $\mathrm{CH}$ cannot be measured. However, boys were at higher risk of $\mathrm{CH}$ than girls. But it is still unknown, and these observations require more epidemiological studies. The present study showed no significant association between $\mathrm{CH}$ and type of delivery. In this study, among 40 patients with $\mathrm{CH}, 28 \%$ (12 cases) and 23.5\% (28 cases) were delivered by NVD and cesarean, respectively. Esmailnasab et al. showed no relationship between type of delivery and $\mathrm{CH}$ (12), while Rezaeian et al. and Khalafi et al. reported an inverse relationship between type of delivery and $\mathrm{CH}$. They indicated that neonates delivered by cesarean have higher risk of $\mathrm{CH}$ than neonates delivered by $\operatorname{NVD}(19,20)$. Some researchers believe that cesarean can increase TSH levels (13). Although in the present study, there was no significant association between $\mathrm{CH}$ and history of parental consanguinity; however, neonates who were born of parents in a consanguineous marriage were at higher risk of $\mathrm{CH}$ compared to others. Previous literature shows that children of Asian families are at higher risk of $\mathrm{CH}$ than other ethnicities (21). It is unclear why the Asian population have a higher risk of $\mathrm{CH}$; it is may be because of consanguineous marriages in this areas (22). The results in another study, also showed no significant relationship between parental consanguinity and $\mathrm{CH}$ (23). In contrast, many other studies such as the study conducted in Shadegan, Iran reported that relationships were found between $\mathrm{CH}$ and parental consanguinity (24). Hence, hypothyroidism is sporadic and in the occurrence of genetic mutations, genetic factors have little role in its development (24). Due to the lack of iodine deficiency in Iran (25) and the declaration of Iran as a country free of iodine deficiency, it can be concluded that genetic and familial factors have more prominent role than environmental factors such as iodine deficiency (12).

According to our findings, the neonates who were born from younger mothers were at higher risk of $\mathrm{CH}$. Abedi et al. and Keshavarzian et al. reported that there was no relationship between age of mother and $\mathrm{CH}(11,24)$. However, the results in another study showed a significant relationship between age of mother and CH (19). Harris et al. concluded that neonates who were born from mothers aged 40 years and older have a higher risk of $\mathrm{CH}$ than younger mothers (21). A maternal age under 35 years has been identified as a risk factor in some studies (8). The results of the present study indicated that the probability of $\mathrm{CH}$ in low-birth height infants is two-fold greater than normal or high height infants. In this regard, Dalili et al. reported that there was no relationship between height and weight at birth and $\mathrm{CH}$ (26). Eftekhari et al. and Abedi et al. reported an inverse relationship between height and weight at birth with $\mathrm{CH}(11,27)$. Weight and height at birth in neonates are dependent on many factors, such as lack of access to accurate nutritional information, pre-pregnancy status and overlapping with other diseases (28).

Our findings showed that there was no association between birth season and $\mathrm{CH}$; however, the neonates who were born in the summer were at higher risk of hypothyroidism compared to those who were born in spring. The results regarding seasonal relationships were consistent with previous literature such as that of Pearce et al. in northern England (29) Dalili et al. (13), Keshavarzian et al (24) and Hashemipour et al. (30) in Iran, while some studies have shown a seasonal variation in the incidence of $\mathrm{CH}$ such as $\mathrm{Gu}$ et al. (31) in Japan, Ordookhani et al. (32) and Rezaeian et al. (19) in Iran. Environmental conditions such as increasing airborne exposures or seasonal dietary changes that could provide a justification, may be reasons of this controversy. It is concluded that differences in climate, viral infections or chemical exposures are important in the differences. Hashemipour et al. found that maximum incidence of $\mathrm{CH}$ was found in July and August. (30). While Rezaeian et al. reported higher incidence of $\mathrm{CH}$ in winter (19). Our findings showed that $\mathrm{CH}$ had no association with time of sampling. However, Mohammadi et al. reported a significant correlation between time of sampling and $\mathrm{CH}$ (33). In most countries, low cooperation of people was indicated as screening weakness because screening should done in 72 hours after child birth (34). According to our findings, there was no correlation between nationality and $\mathrm{CH}$. Regarding the study limitation, the number of participants with hypothyroidism was very low and access to patient records and incomplete information was another limitation of the study. 


\section{Conclusions}

In general, although the studied variables did not have any statistical association with $\mathrm{CH}$, they have an important role in the disease. It is recommended that thyroid screening programs should be followed seriously. Also, more comprehensive studies are needed to be carried out for recognizing related factors on the incidence of congenital hypothyroidism. Since consanguineous marriages are frequent in the province, and it may be a major contributory factor, future studies should be conducted on the genetic causes.

\section{Acknowledgments:}

The authors would like to thank the health center mangers for their collaboration in the study. The present article was extracted from a research project grant no. 7927 which is supported by Zahedan University of Medical Sciences.

\section{Conflict of Interest:}

There is no conflict of interest to be declared.

\section{Authors' contributions:}

All authors contributed to this project and article equally. All authors read and approved the final manuscript.

\section{References:}

1) Fan X, Chen S, Qian J, Sooranna S, Luo J, Li C, et al. Incidence and Interrelated Factors in Patients With Congenital Hypothyroidism as Detected by Newborn Screening in Guangxi, China. Glob Pediatr Health. 2015. doi: 10.1177/2333794X14567193. PMID: 27335934, PMCID: PMC4784601.

2) Ghaemi N, Bagheri S, Elmi S, Rezaee SM, Elmi S, Sayyar RE. Delayed Diagnosis of Hypothyroidism in Children: Report of 3 Cases. Iranian Red Crescent Medical Journal. 2015; 17(11): e20306. doi: 10.5812/ircmj.20306. PMID: 26734478, PMCID: PMC4698140.

3) Löf C, Patyra K, Kuulasmaa T, Vangipurapu J, Undeutsch H, Jaeschke H, et al. Detection of novel gene variants associated with congenital hypothyroidism in a Finnish patient cohort. Thyroid. 2016; 26(9): 1215 24. doi: 10.1089/thy.2016.0016.

4) Singh A, Purani C, Mandal A, Mehariya KM, Das RR. Prevalence of Thyroid Disorders in Children at a Tertiary Care Hospital in Western India. Journal of clinical and diagnostic research: JCDR. 2016; 10(2): SC01-4. doi: 10.7860/JCDR/2016/16315.7189. PMID: 27042544, PMCID: PMC4800610.

5) Li M, Eastman CJ. Neonatal TSH screening: is it a sensitive and reliable tool for monitoring iodine status in populations? Best Practice \& Research Clinical Endocrinology \& Metabolism. 2010; 24(1): 63-75. doi: 10.1016/j.beem.2009.08.007. PMID: 20172471.

6) Saleh DS, Lawrence S, Geraghty MT, Gallego PH, McAssey K, Wherrett DK, et al. Prediction of congenital hypothyroidism based on initial screening thyroid-stimulating-hormone. BMC pediatrics. 2016; 16(1): 24. doi: 10.1186/s12887-016-0559-0.

7) Dorreh F, Yousefi P, Javaheri J, Eshrati B, Amiri Z. Evaluation of 6 years performance of screening program of congenital Hypothyroidism in Markazi Province (2012-2006). Arak Medical University Journal. 2013; 16(8): 39-45.

8) Namakin K, Sedighi E, Sharifzadeh G, Zardast M. Prevalence of congenital hypothyroidism In South Khorasan province (2006-2010). Journal of Birjand University of Medical Sciences. 2012; 19(2): 191-9.

9) Zeinalzadeh AH, Kousha A, Akhtari M, Talebi M. Screening for Congenital Hypothyroidism in East Azerbaijan province, IRAN. Journal of Kerman University of Medical Sciences. 2011; 18(4): 301-8.

10) Akha O, Shabani M, Kowsarian M, Ghafari V, Sajadi Saravi S. Prevalence of congenital hypothyroidism in Mazandaran Province, Iran, 2008. Journal of Mazandaran University of Medical Sciences. 2011; 21(84): 63-70.

11) Abedi M, Shahsavari S, Salehi R, Hedayati NS, Nasrollahi S, Sadeghi S, et al. The Study Of Prevalence And Risk Factors Of Hypothyroidism In Newborn Screening Program In Sanandaj City In 2009-2014. Zanko Journal of Medical Sciences. 2015; 15(47): 46-51.

12) Esmailnasab N, Moasses Ghaffari B, Afkhamzadeh A. Investigation of the risk factors for congenital hypothyroidism in the newborns in Kurdistan Province. Scientific Journal of Kurdistan University of Medical Sciences. 2012; 17(4).

13) Dalili S, Rezvany SM, Medghalchi A, Mohammadi H, Dalili H, Mirzanejad M, et al. Congenital hypothyroidism: a review of the risk factors. Acta Medica Iranica. 2012; 50(11): 735. PMID: 23292624. 
14) Delavari AR, Yazdani Z. Laboratory protocol of neonatal thyroid screening. Tehran: Disease Control Center, Ministry of Health and Medical Education. 2004.

15) Anastasovska V. High incidence of congenital hypothyroidism in one region of the Republic of Macedonia. Balkan Journal of Medical Genetics. 2014; 17(1): 31-5. doi: 10.2478/bjmg-2014-0024.

16) Medda E, Olivieri A, Stazi MA, Grandolfo ME, Fazzini C, Baserga M, et al. Risk factors for congenital hypothyroidism: results of a population case-control study (1997-2003). European Journal of Endocrinology. 2005; 153(6): 765-73. doi: 10.1530/eje.1.02048.

17) Rezaeian S, Moghimbeigi A, Esmailnasab N. Gender differences in risk factors of congenital hypothyroidism: an interaction hypothesis examination. Int J Endocrinol Metab. 2014; 12(2): e13946. doi: 10.5812/IJEM.13946. PMID: 24790630, PMCID: PMC4005272.

18) Ebadi SA, Afshar M. Epidemiology of hypothyroidism in Gilan. Feyz. 2004; 8(3): 30-5.

19) Rezaeian S, Poorolajal J, Moghimbegi A, Esmailnasab N. Risk factors of congenital hypothyroidism using propensity score: a matched case-control study. J Res Health Sci. 2013; 13(2): 151-6. PMID: 24077472.

20) Khalafi A, Jafarisani M, Alizadeh $H$, Hasanzadeh M, Jafarisani A, Kameli M, et al. Screening of congenital hypothyroidism in the Torbat-E-Heydariyeh in 1390. Journal of Torbat Heydariyeh University of Medical Sciences. 2014; 1(4): 40-5.

21) Harris KB, Pass KA. Increase in congenital hypothyroidism in New York State and in the United States. Molecular genetics and metabolism. 2007; 91(3): 268-77. doi: 10.1016/j.ymgme.2007.03.012.

22) Hamamy H, Antonarakis SE, Cavalli-Sforza LL, Temtamy S, Romeo G, Ten Kate LP, et al. Consanguineous marriages, pearls and perils: Geneva international consanguinity workshop report. Genetics in Medicine. 2011; 13(9): 841-7. doi: 10.1097/GIM.0b013e318217477f.

23) Valizadeh M, Mazloomzadeh S, Niksirat A, Shajari Z. High Incidence and Recall Rate of Congenital Hypothyroidism in Zanjan Province, a Health Problem or a Study Challenge? International Journal of Endocrinology and Metabolism. 2011; 9(4): 338-42.

24) Keshavarzian E, Valipoor AA, Maracy MR. The incidence of congenital hypothyroidism and its determinants from 2012 to 2014 in Shadegan, Iran: a case-control study. Epidemiol Health. 2016; 38: e2016021. doi: 10.4178/epih.e2016021. PMID: 27283138, PMCID: PMC4967912.

25) Hasani N, Dehghan B, Amini M, Heidari K, Sajadi A, Ajami A, et al. Congenital hypothyroidism; is there any familial component? Journal of Isfahan Medical School. 2009; 27(94): 134-41.

26) Dalili S, Rezvani SM, Dalili H, Amiri ZM, Mohammadi H, Kesh SA, et al. Congenital hypothyroidism: etiology and growth-development outcome. Acta Med Iran. 2014; 52(10): 752-6. PMID: 25369009.

27) Eftekhari N, Asadikaram Gh, Khaksari M, Salari Z. The prevalence rate of congenital hypothyroidism in Kerman/Iran in 2005-2007. Journal of Kerman University of Medical Sciences. 2015.

28) Razi S, VaziriNejad R, Rezaeian M, Sheikh Fathollahi M, Manshouri A, Goujani R, et al. Survey of Birth Weight in Newborns among Mothers with and Without a Common Underlying Disease in Rafsanjan Niknafs Maternity in 2011-2012. JRUMS. 2014; 13(4): 323-38.

29) Pearce MS, Korada M, Day J, Turner S, Allison D, Kibirige M, et al. Increasing incidence, but lack of seasonality, of elevated TSH levels, on newborn screening, in the North of England. Journal of thyroid research. 2010; 2010. doi: 10.4061/2010/101948.

30) Hashemipour M, Amini M, Kelishadi R, Hovsepian S, Haghighi S, Hosseini M, et al. Seasonal variation in the incidence of congenital hypothyroidism in Isfahan, Iran. Saudi Med J. 2007; 28(10): 1582. PMID: 17914523.

31) $\mathrm{Gu} \mathrm{YH}$, Kato T, Harada $\mathrm{S}$, Inomata H, Saito T, Aoki K. Seasonality in the incidence of congenital hypothyroidism in Japan: gender-specific patterns and correlation with temperature. Thyroid. 2007; 17(9): 869-74. doi: 10.1089/THY.2006.0317.

32) Ordookhani A, Padyab M, Goldasteh A, Mirmiran P, Richter J, Azizi F. Seasonal variation of neonatal transient hyperthyrotropinemia in Tehran province, 1998-2005. Chronobiology international. 2010; 27(910): 1854-69. doi: 10.3109/07420528.2010.516046.

33) Mohammadi E, Baneshi MR, Nakhaee N. The Incidence of Congenital Hypothyroidism in Areas Covered by Kerman and Jiroft Universities of Medical Sciences, Iran. 2012.

34) Asadi Karam G, Aminzadeh F, Sheikh Fathollahi S, Masoud Pour N, Reyahi B, Yusefnia N, et al. High recall rate in the screening program for congenital hypothyroidism in Rafsanjan. Iranian journal of Endocrinology and Metabolism. 2004; 6(1): 21-6. 